\title{
Students' Characteristics as Determinants of Academic Performance in Economics among Fatima High School in Irewole Local Government Area, Osun State, Nigeria: Theoretical Approach and Empirical Evidence
}

\author{
Aransi, Waliyi Olayemi \\ Head of Social Science department,Fatima Government High School, Ikire, Osun State, Nigeria. \\ Email: omoaransi@yahoo.com
}

\begin{abstract}
Received: 19 September 2019; Revised: 21 October 2019; Accepted: 30 October 2019; Published: 15 November 2019
Abstract: The importance of students' academic performance as a single strongest factor in the determination of the school tone as well as overall success of the school activities in all ramifications cannot be overemphasized. In the light of this, this study aimed at examining the influence of students' qualities on academic performance in Economics. The expost facto research design was adopted. However, one-hundred and eight two (182) out of one-hundred and ninety two (192) Grade 10 (that is Senior Secondary School Students one) who sat for Unified Promotion Examination in Fatima High school for 2017/2018 academic session were used. The empirical findings emanated from Analysis of Co-variance (ANCOVA), Correlation analysis and t-test statistics revealed that there was no interactive influence of attendance rate and gender on academic performance, positive linear but weak association between aggregate attendance and performance in economics was observed, while significant relationship existed between students with high attendance rate that is those having seventy-five percent and above $(\geq 75 \%)$ as compared with their counterparts having less than seventy-five percent $(<75 \%)$ respectively. It was concluded that regularity and punctuality of the students not only in the school but also in the classroom during teaching-learning interaction between the teachers and the students need to be accorded great priority so as to maintain the good tone of any academic institutions. It was recommended that external reinforcement like an award to the most punctual and regular student for the academic session, inclusion of attendance level criterion for students coming on transfer from sister schools, and formulation and implementation of minimum attendance standard for students before he/she would be qualified to seat for the examination among others be given quality attention.
\end{abstract}

Keywords: Students' Characteristics, Statutory Records, Academic Performance.

\section{Introduction}

In a formal academic setting, learning is seen as a process through which a learner experiences relative permanent change in behaviour and skills as a result of his/her exposure to either hidden or formal content of the school curriculum. This kind of learning may not be directly observed and measured unless learners are subjected to periodic assessment by the subject teachers and public examinations conducted by external bodies like the National Examinations Council (NECO), and West African Examinations Council (WAEC) among others. This will ascertain the extent to which the students have internalised the learning experiences in the school subjects through a variable called an academic performance. Therefore, academic performance could be described as the learning outcomes that manifest in the students which encompass an improvement in knowledge, skills as well as accumulation of ideas through courses of study both within and outside the classroom setting or learning environments. It is a means of ascertaining the extent to which stakeholders of education more importantly students, teachers and academic institutions have attained the highlighted educational objectives and goals which may vary across the students as well as academic institutions over a period of time. The prevailing fluctuations in the academic performance of secondary school students at macro coverage in public examinations needs the attention of the stakeholders of education. This is because, the report from the West African Examinations Council (WAEC) revealed that twenty-seven point fifty three percent $(27.53 \%)$ of the students who sat for the WASSCE in 2005 obtained five credits, English language and Mathematics inclusive. In 2006, the figure declined to fifteen point fifty six percent (15.56\%). Besides, twentyfive point fifty four percent $(25.54 \%)$ had five credit and above in 2007 which was less than the figure recorded in 2005 , the worst performance of thirteen point seventy six percent $(13.76 \%)$ was observed in 2008. There 
was a slight improvement in 2009, when twenty-five point ninety nine percent (25.99\%) passed the examination, the trend reduced to twenty-point four percent (20.4\%) in 2010 (Olorundare, 2011). However, there was a slight improvement in performance of students in the aforementioned examination between 2014 and 2018 as compared with the previous years. It was revealed that in 2014 and 2015, the percentage of candidates that obtained five credits and above including English Language and Mathematics in the WASSCE were thirty-one point twenty eight (31.28\%) and thirty-eight point sixty eight percent (38.68\%) respectively. The figure improved to fifty-two point ninety seven percent (52.97\%), fifty-nine point twenty percent (59.20\%) and forty-nine point ninety percent (49.90\%) in the years 2016,2017 and 2018 respectively. Besides, on the basis of state ranking nationwide in 2018, it was reported that none of the six states (Osun, Oyo, Ogun, Lagos, Ondo, and Ekiti) within South-West Zone of Nigeria was among the first top ten in the performance list (WAEC, 2018). On micro level, the performance of students in Economics as revealed in the WASSCE results analysis (as shown in the table 1 below) with respect to the school under investigation between 2009 and 2018 academic session presents similar picture.

Table 1.

Showing the analysis of the grades obtained in Economics by candidates sat for WASSCE in Fatima High school between 2009 and 2018.

\begin{tabular}{|c|c|c|c|c|c|}
\hline Year & Total Registered & $\mathbf{A}_{1}-\mathbf{C}_{6}$ & $\mathbf{D}_{7}$ & $\overline{\mathbf{E}_{8}}$ & $\mathbf{F}_{9}$ \\
\hline 2009 & 54 & $8(14.82 \%)$ & $1(1.85 \%)$ & $4(7.41 \%)$ & $41(75.92 \%)$ \\
\hline 2010 & 69 & -----_------ & $7(10.10 \%)$ & $6(8.70 \%)$ & $56(81.20 \%)$ \\
\hline 2011 & 60 & $2(3.33 \%)$ & $5(8.33 \%)$ & $7(11.67 \%)$ & $46(76.67 \%)$ \\
\hline 2012 & 89 & $12(13.48 \%)$ & $7(7.87 \%)$ & $21(23.60 \%)$ & $49(55.05 \%)$ \\
\hline 2013 & 54 & $13(24.07 \%)$ & $10(18.52 \%)$ & $20(37.04 \%)$ & $11(20.37 \%)$ \\
\hline 2014 & 183 & -_-_-_-_--- & $1(0.55 \%)$ & $2(1.09 \%)$ & $180(98.36 \%)$ \\
\hline 2015 & 184 & --------- & -_--------- & --------- & $183(99.46 \%)$ \\
\hline 2016 & 50 & $5(10.00 \%)$ & --------- & $4(8.00 \%)$ & $40(80.00 \%)$ \\
\hline 2017 & 06 & $3(50.00 \%)$ & $3(50.00 \%)$ & - - - & -_-_-_-_-_ \\
\hline 2018 & 68 & $67(98.53 \%)$ & $1(1.47 \%)$ & -_-_-_-_- & -_-_-_-_-_ \\
\hline
\end{tabular}

Out of fifty-four (54) candidates that sat for WASSCE in Fatima College in 2009, eight (8) representing $14.82 \%$ had between $\mathrm{A}_{1}$ to $\mathrm{C}_{6}$, one (1) and four (4) of them which amounted to $1.85 \%$ and $7.41 \% \mathrm{had}_{7} \mathrm{D}_{7}$ and $\mathrm{E}_{8}$ respectively, while, forty-one (41) of them failed by having $\mathrm{F}_{9}$. The worst results was recorded in year 2010 in which no candidates had either distinction (A), excellent (B) or good (C), result with fifty-six (56) out of sixtynine (69) who registered during this period had $\mathrm{F}_{9}$ as grade while seven (7) and six (6) representing $10.1 \%$ and $8.7 \%$ of the aggregate participants had $\mathrm{D}_{7}$ and $\mathrm{E}_{8}$ respectively.

Besides, the number of students who were enrolled for the said examination reduced in 2011. The analysis indicated that two (2), five (5), seven (7) and forty-six (46) of the participants representing 3.33\%, 8.33\%, $11.67 \%$ and $76.67 \%$ had grades ranging from between $\mathrm{A}_{1}$ to $\mathrm{C}_{6}, \mathrm{D}_{7}, \mathrm{E}_{8}$ and $\mathrm{F}_{9}$ respectively. In 2012 , despite the fact that the number of candidates registered increased as compared with the previous years, considerable improvement was recorded from their grades. Fifty-four (54) candidates registered in 2013, out of which thirteen (13) amounting to $24.07 \%$ obtained grades ranges between $\mathrm{A}_{1}$ to $\mathrm{C}_{6}$. Also, the school experienced proliferation in registration for the examination under consideration as well as massive failure in 2014 and 2015 due to introduction of new policy by state government called re-classification of public school which led to merging of some schools and conversion of some from single sex like Fatima College to mixed school, change of public boarding to day among others. During this period, one-hundred and eighty three (183) and one-hundred and eighty four (184) candidates registered respectively. However, one-hundred and eighty three (183) out of one-hundred and eighty four (184) candidates failed while the result of one (1) participant was completely withheld in year 2015. The least number of candidates that is six (6) registered for Economics in 2017. Finally, recent records showed that all candidates passed this subject in 2018 . However, a number of factors are responsible for the identified instability in academic performance among students even not only in the public examinations (that is Standardized Test like WAEC) as reflected above but also in teacher-made test. These may be traceable to other factors such as school, parents and government among others.

Meanwhile, there is no gain saying in the fact that schools are established for the purpose of attaining educational objectives through joint and complementary efforts of human and material resources. In the light of this, classroom environment, either physical or social, is a vital resources that can affect academic 
achievement of the learners. Falsario, Muyong and Neuvaespana, (2014) were of the view that physical classroom environment entails the arrangement of chairs, tables, fixtures and pieces of furniture, painting, lighting and ventilation while the social environment connotes the leadership styles exhibited by the teacher and the mode of students' participation and interaction. This has made Oginni, Awobodu, Alaka, and Saibu, (2013) to argue that physical environment such as availability of adequate laboratory coupled with appropriate materials, equipment and apparatus is a necessary condition for the effective implementation of science curriculum. Furthermore, Classroom environment according to Boniface (2018), has the potential to determine the learners' level of interest, degree of motivation and level of commitment in both curriculum and extra curriculum activities such that favourable classroom environment coupled with students' interest would significantly predict academic achievement. The reason for this is that when a classroom environment is favourable, the students are comfortable and likely to get much information compared to those who are uncomfortable. In addition, when a classroom is well furnished with physical facilities coupled with an appealing social and psychological climate, learners become attracted to and interested in the activities going on in such a classroom environment. On the other hand, unfavourable classroom environment may discourage learners by dampening their interest and morale which might in turn hinder academic achievement. This is consequent upon the fact that the decision by learners to exert extra effort and engage in any academic engagement is a function of the level of interest as well as other prevailing motivational instances put in motion. On the part of teachers, Ouma, and Munyua, (2018) concurred that teachers' working conditions in terms of provision of houses, adequate infrastructural facilities, teaching and learning resources and professional development among others are great determinants of students' academic performance. Therefore, poor working conditions and inadequate teaching and learning materials were identified as the major demotivators of teachers towards good students' academic performance. Similarly, Alufohai, (2016) corroborated that teachers' qualification and instructional materials either locally made or readymade significantly influence student's academic achievement. Therefore, it could be deduced that qualified teachers are likely to outperform their unqualified counterparts in the course of teaching-learning process. This is premised on the belief that qualified teachers might have had a better exposure in methods or techniques of teaching as well as acquire professional knowledge needed for teaching which include, application of the learning experiences and content, understanding of learners' individual characteristics, knowledge of educational contexts, knowledge of educational aims, goals, and purposes, and pedagogical content knowledge to mention a few when they were in teacher education training schools and during the in-service or on-the-job trainings.

Besides, Kosoko-Oyedeko (2008) was of the opinion that teacher's self-efficacy, training and attitude played a vital role in the pupil's academic achievement. In the same vein, Daso (2013) submitted that there is significant relationship among teachers' attitude, teachers' method of teaching and students' academic achievement. Farooq, Chaudhry, Shafiq and Berhanu (2011) identified socio-economic status (SES) and parents' education as factors outside school which have potential to exert significant effect on students' overall academic achievement in school subjects. High and average socio-economic level affects the performance more than the lower socio-economic level. This proposition failed to take into cognizance school type such a teacher or a learner belongs to. However, there is no consensus in the literature with respect to the effect of school types on academic performance such that scholars like Ajayi, (2006), Philias and Wanjobi (2011) reiterated that school type (private or public) has effect on the academic performance of students. Due to this, Bonsu (2016) argued that private schools were not only better resourced but also had parents of pupils with higher socioeconomic status and at the same time were prepared to be more involved in their children's education. In contrary, other scholars among whom are Alimi, Ehinola, and Alabi, (2012), Aransi, (2018) reported no significant difference in academic performance of students in the two types of secondary schools. This submission according to Aransi, (2018) could be as a result of the availability of professionally qualified teachers in public schools which enhances not only in preparing students adequately well for both academic and non-academic activities but also in improvising the teaching and learning resources in such a way as to enable public school students to compete keenly with their counterparts in private schools. It should be noted that these arguments neglect the instrumentality of school location on students' performance.

On this note, Owoeye, and Yara, (2011) confirmed that students in urban areas had better academic achievement than their rural counterparts. This according to Odinko (2002) was premised on the ground that schools located in urban areas are better positioned to attract more quality students and teachers who exhibit the readiness to take academic business seriously. Going in the same direction, Okonkwo (2002) observed that students in rural areas had better academic performance than their counterparts in urban school settings. In another development, Considine and Zappala (2002) affirmed that the geographical location of the school (that 
is urban and rural) does not significantly predict outcomes in school performance. The dichotomy in the outcomes emanated from previous works may in part be attributed to factors like uneven distribution of resources, condition of infrastructural facilities and social amenities, problem of qualified teachers, refusal of appointment or not intend to perform well in isolated villages, nonchalant attitude of some people in either rural or urban communities to schooling, and technique of supervising and inspecting school vis-à-vis school records among others. Meanwhile, school records are means of providing useful information about the input used in the school system and output realized from the same system which involves physical, financial and human resources and at the same time relate to the students, the teachers, the school and the educational system in general. These comprise both statutory and non-statutory records. Statutory school records are the records which are mandatory under the education law to be kept by all educational institutions most especially at primary and secondary school levels. These comprise admission register, diary of works, log book, lesson note or plan, time-table, visitor's book, corporal punishment book, continuous assessment book, time book, testimonial and transfer certificate book, examination records, and daily attendance register to mention a few. However, there is no clear cut in the education law with respect to the role being played by each of the school records towards academic achievement in the school system.

Although, the role of attendance could not be overemphasized at all levels of education, this is because some tertiary institution spell it out in an unequivocal terms the percentage of attendance a students should have before he/she would be allowed and qualified to sit for the examination on such a course. This is to say that there is correlation between attendance rate in a course and performance level in general. In the light of this, Robert (2015) submitted that the monitoring tools used for students' attendance in Universal Secondary Education Schools in Serere, Soroti, Kumi and Ngora districts in Teso sub-region; North Eastern Uganda are effective and there was a very positive relationship between student attendance and academic performance. This is advantageous due to the fact that it has the potential to bring about improvement in the students' academic performance, add to the standard of the schools, build the students' social as well as emotional skills, improve students' knowledge and employment skills, and reduce the risks of dropout. The author argued further that decline in students' school attendance may have adverse effect in so many dimensions. Such that it leads to poor academic performance, students drop out, graduating half-baked students, poor curriculum coverage and loss of interest in learning. For school, it affects the school image, lower the students' enrolment, transfer of students by parents, wastage of teachers' and administrators' time and affects the tertiary institutions enrolment. Narula and Nagar (2013) found that there is significant positive correlation between the students' performance and their attendance among undergraduate students in India. The study conducted by Aden, Yahye and Dahir, (2013) revealed a strong positive relationship between student's attendance and academic performance among students of the Faculty of Business and Accountancy in SIMAD University, Somalia. Keci and Guleker (2013) were of the view that students with good attendance might even stand to receive failing grades. This shows that students are predisposed to receive failing grades regardless of the attendance. Nevertheless, it suggests that the higher the attendance is, the lower the probability of receiving failing grades appears to be as well. Besides, Fadelelmoula (2018) reported that there was positive but insignificant correlation between attendance and examination performance in the courses like Cardiopulmonary Anatomy and Physiology, Cardiology and Electrocardiography, Respiratory Care Science II as well as exercise Physiology and Pulmonary Rehabilitation at Almaarefa Colleges for Science and Technology, Riyadh, Saudi Arabia. Using modern approach to the collection of data on attendance of undergraduate students that is through smartphone sensors and bluetooth, Kassarnig, Bjerre-Nielsen, Mones, Lehmann, and Lassen (2017) demonstrated that early and consistent class attendance strongly correlates with academic performance. In spite of the great position that is expected of attendance to occupy as a statutory record, there is no consensus in the literature with respect to relationship between students' attendance and performance. Even majority of the previous works were based on students' in tertiary institutions in other part of the world, while, attention has not been fully tailored towards the direction of relationship between these variables at secondary school level. Hence, this research work stands to fill the identified gap in the literature and at the same time contribute to the existing body of knowledge. It is against this background that the study is designed to answer the following research questions and achieve the under listed research objectives.

\subsection{Research Questions}

i. To what extent do gender quality and attendance rate interactively influence the academic performance in Economics among Fatima High School students? 
ii. What is the individual contribution of gender quality and attendance rate on the students' academic performance in Economics among Fatima High School students?

iii. What is the strength of relationship between attendance rate and students' academic performance in Economics among Fatima High School students?

iv. Is there any difference between academic performances of Fatima High School students with high and low attendance rate?

\subsection{Objectives of the Study}

i. To evaluate the extent to which gender quality and attendance rate interactively influence the academic performance in Economics among Fatima High School students.

ii. To assess the individual contribution of gender quality and attendance rate to academic performance in Economics among Fatima High School students.

iii. To ascertain the relationship between students' attendance rate and academic performance in Economics among Fatima High School students.

iv. To examine the difference between academic performances of Fatima High School students with high and low attendance rate.

\section{Conceptual Framework}

The conceptual framework designed for this research work indicates that aside from students' quality other intervening variables like parental background, parenting styles, government factors, and societal factors among others, may be responsible for students' academic performance in the school subjects. On the part of school where the student is, environment of the school vis-à-vis how ambient is it, when considering teaching and learning process, occupy an important place for teachers to discharge their duties effectively as well as for shaping learners disposition towards academic tasks ahead of them. This is because, academic performance of students could be predicated on the degree of safeness and orderliness of the facilities provided within the school environment. Conducive school atmosphere in conjunction with good teacher-student relationship, employment of suitable and relevant instructional aids, and availability of qualified personnel in school could motivate and stimulate the students to work hard which would in turn enhance their academic performance. In addition, the kind of teaching and learning environment and class size a learner finds himself/herself depends on the school type such a child attends which is a function of financial status of the parents and government policy towards establishment and maintenance of standard of the school type. Sometimes, we may observe that despite the diversity in learning environment across schools, traits like gender, age, and emotional status of the learners may exert significant effect irrespective of the prevailing school factors. This relationship among school factors, student's quality and academic performance in conjunction with some intervening variables are depicted in the figure 1 below;

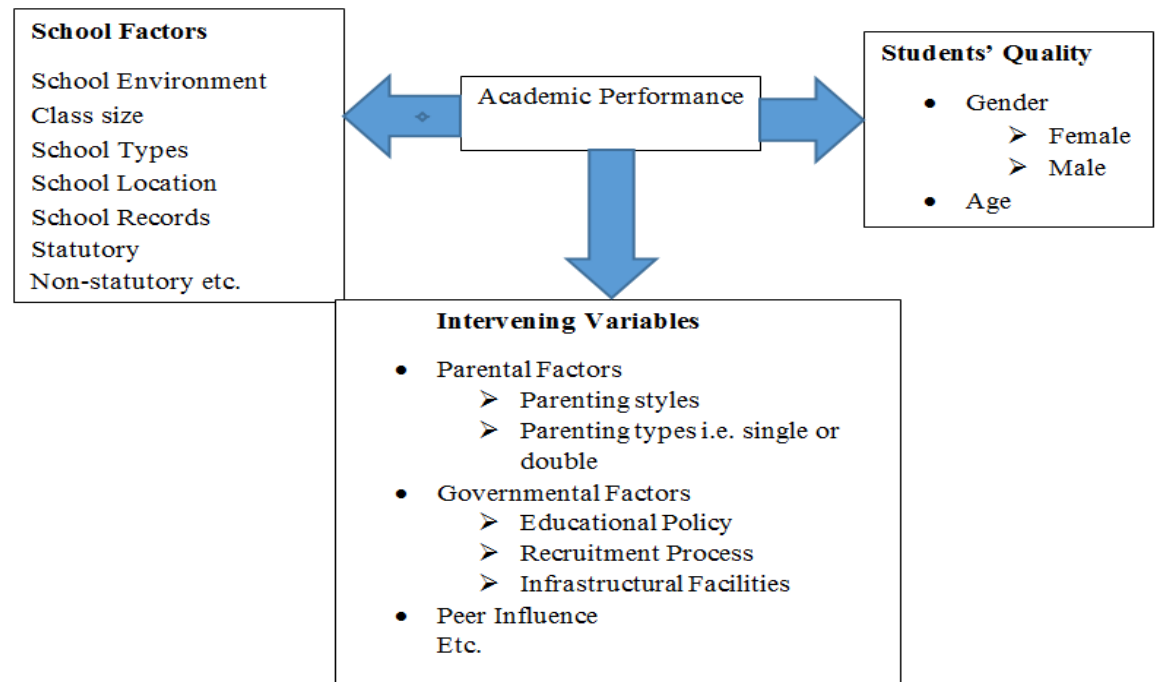

Figure-1. The Chart Showing School Factors and Students' Quality as well as Intervening Variables as Determinants of Academic Performance 


\section{Methodoloy}

\subsection{Research Design}

The study adopted ex-post facto research design. The researcher considers this design adequate and suitable for the work due to its unique and in-built features such that it is useful in reporting what has happened or what is happening without having substantive control over the variables of interest. In ex-postfacto design, however, the regressand (dependent variable) is observed while several other regressors (independent variables) may be looked for. Hence, the observation of the regressand may happen before, after or concurrently with the regressors. In the light of this, gender and punctuality as well as regularity of the students which was used to proxy attendance rate had been determined before the conduct of promotion examination championed by the Osun State Ministry of Education in year 2018.

\subsection{Target Population and Sampling Procedure}

All students who offered Economics and sat for the Unified Promotion Examination (UPE) during 2017/2018 academic session in Fatima High schools in Irewole Local Government Area of Osun State formed the target population for the study. However, one-hundred and eighty two (182) out of one-hundred and ninety two (192) Grade 10 (that is Senior Secondary School Students one) who sat for the said Unified Promotion Examination were sampled with the aid of purposive sampling technique as key part of nonprobability sampling technique. The reason for using this set of students was that Economics was made compulsory for all of them irrespective of the stream and at the same time the school authority embarked on sequential inspection and supervision of all forms of statutory records for their level.

\subsection{Sources and Measurement of Variables}

The secondary data extracted from various statutory records of the Fatima high school was used. The variables of interest were attendance level, performance and gender trait of the students involved. These variables were obtained from various sources such that both attendance level and gender quality were sourced from school attendance registers of each of the classes which belonged to that stream while scores in Economics as proxy by performance was obtained from Unified Promotion Examination (UPE) records of the school sent from Osun State Ministry of Education, Osogbo in 2018. Besides, attendance rate was measured as summation of number of days the students were present and punctual in the school from the beginning of the 2017/2018 academic session to the end $\left(\mathrm{X}_{\mathrm{i}}\right)$ divided by number of days the school was opened for academic activities $\left(\mathrm{Y}_{\mathrm{i}}\right)$ multiplied by one-hundred (that is $\frac{\mathrm{Xi}}{\mathrm{Yi}} \times \frac{100}{1}$ where $i$ ranges from $1-n$ ). From this formular, any students having less than seventy-five percent (75\%) was considered as having low attendance rate. And if otherwise, it is considered to be high. Also, gender and academic performance variables were measured with the aid of categorical measurement such that zero (0) was used for the presence of female attribute and one (1) otherwise and students' actual scores in Economics were used to proxy academic performance respectively.

\subsection{Method of Analysis}

The components of inferential statistics were used for data analysis. This was done on the basis of the research questions raised, research objectives designed for the study as well as research hypotheses tested. For instance, in order to answer research questions number one and two in conjunction with objectives one and two which originated from the said questions, Analysis of Covariance (ANCOVA) was used, correlation analysis was used to answer research question three. While, t-test statistics was employed to answer research question four at one percent and five percent (1\% and 5\%) levels of significant.

\section{Empirical Result \\ Research Question I.}

To what extent do gender quality and attendance interactively influence the academic performance in Economics among Fatima High School students? 
Table 2.

Analysis of Covariance (ANCOVA) result showing interactive influence of gender quality and attendance rate on the academic performance in Economics among Fatima High School students

Tests of Between-Subjects Effects

Dependent Variable: Academic Performance

\begin{tabular}{|l|l|l|l|l|l|}
\hline Source & Type III Sum of Squares & df & Mean Square & F & Sig. \\
\hline Corrected Model & $189.797^{\text {a }}$ & 2 & 94.899 & 1.834 & .163 \\
\hline Intercept & 10734.670 & 1 & 10734.670 & 207.508 & .000 \\
\hline Gender * Attendance & $\mathbf{1 8 9 . 7 9 7}$ & $\mathbf{2}$ & $\mathbf{9 4 . 8 9 9}$ & $\mathbf{1 . 8 3 4}$ & $\mathbf{. 1 6 3}$ \\
\hline Error & 9259.923 & 179 & 51.731 & & \\
\hline Total & 250607.000 & 182 & & & \\
\hline Corrected Total & 9449.720 & 181 & & & \\
\hline
\end{tabular}

Note: a. R Squared $=.020$ (Adjusted R Squared $=.009$ )

Table 2: Shows the interactive effect of attendance rate and gender as covariate and factor respectively on students' academic performance in Economics. Therefore, the interaction source is in bold face and labelled Gender * Attendance in which the results suggested that the interaction is not statistically significant. This is because, the probability value of $p(0.163)$ was greater that alpha value of $\alpha(0.05)$ with $F(2,179)=1.834, p$ $=0.163$. That is, $p(0.163)>\alpha(0.05)$. This implies that the gender of the students and attendance correspondingly working together are insignificant in predicting academic performance in Economics. Hence, there is no significant interactive influence of gender quality and attendance rate on academic performance in Economics.

Table 3.

Test for the underlying assumption of homogeneity of variance

Levene's Test of Equality of Error Variances ${ }^{a}$

Dependent Variable: Academic Performance

\begin{tabular}{|l|l|l|l|}
\hline $\mathbf{F}$ & df1 1 & df2 & Sig. \\
\hline 4.046 & 1 & 180 & .176 \\
\hline
\end{tabular}

Note: Tests the null hypothesis that the error variance of the dependent variable is equal across groups. a. Design: Intercept + Gender * Attendance

Table 3: Indicates the Levene's Test of Homogeneity of Variance. We can conclude that the underline assumption of homogeneity of variance for the one-way ANCOVA has been met-as evidenced by $\mathrm{F}(1,180)=$ 4.046. That is, $\mathrm{p}(0.176)>\alpha(0.05)$. The condition was that if the interaction is significant - the results from an ANCOVA are not meaningful and ANCOVA should not be conducted. This is because, a significant interaction between the covariate (attendance) and the factors (gender) suggests that the difference on the dependent variable (academic performance) among groups vary as a function of the covariate (attendance).

Research Question II: What is the individual contribution of gender quality and attendance to academic performance in Economics among Fatima High School students?

Table 4.

Analysis of Covariance (ANCOVA) result showing individual impact of gender quality and attendance rate on the academic performance in Economics among Fatima High School students.

Tests of Between-Subjects Effects

Dependent Variable: Academic Performance

\begin{tabular}{|l|l|l|l|l|l|}
\hline Source & Type III Sum of Squares & df & Mean Square & F & Sig. \\
\hline Corrected Model & $254.007^{\text {a }}$ & 2 & 127.004 & 2.472 & .087 \\
\hline Intercept & 10818.667 & 1 & 10818.667 & 210.592 & .000 \\
\hline Gender & $\mathbf{1 8 9 . 2 9 3}$ & $\mathbf{1}$ & $\mathbf{1 8 9 . 2 9 3}$ & $\mathbf{3 . 6 8 5}$ & $\mathbf{. 0 0 7}$ \\
\hline Attendance & $\mathbf{4 8 . 5 1 8}$ & $\mathbf{1}$ & $\mathbf{4 8 . 5 1 8}$ & $\mathbf{. 9 4 4}$ & $\mathbf{. 3 3 2}$ \\
\hline Error & 9195.712 & 179 & $\mathbf{5 1 . 3 7 3}$ & & \\
\hline Total & 250607.000 & 182 & & & \\
\hline Corrected Total & $\mathbf{9 4 4 9 . 7 2 0}$ & 181 & & & \\
\hline
\end{tabular}

Note: a. R Squared $=.027$ (Adjusted R Squared $=.016$ ) 
Table 4 shows output for the univariate general linear model which contains main effect of gender and attendance as independent variable on academic performance in Economics. The variables like gender and attendance as well as other source of variance are listed in the left column of the table. However, for each source of variance, there are several test statistics.

In order to ascertain the influence of each of the independent variables that is, gender and attendance, the F Statistics and its associated significance level were used. By examining the covariate, i.e. attendance rate, the $F(0.944)$ and its associated significance level (0.332) indicate that there is no significant linear relationship between attendance of students and academic performance in Economics among Fatima high school. This is because, the probability value of $p(0.332)$ was greater than alpha value of $\alpha(0.05)$ with $F(0.944)$.

However, gender as next source of variance, provides the $F(1,179)=3.685$, That is, $\mathrm{p}(0.007)<\alpha(0.05)$. Hence, there is significance between students' gender quality and academic performance. In order to compute the measure of association between gender quality and performance, we employed omega squared (G) $\left.{ }^{2}\right)$ method as given below;

$$
\mathrm{GO}^{2}=\frac{\text { SSB }-(\mathrm{K}-1) \mathrm{MSW}}{\mathrm{SST}+\mathrm{MSW}}=\frac{189.293-(2-1) 51.373}{9449.720+51.373}=\frac{137.92}{9501.093}=0.02
$$

Therefore, outcome from omega square that is $\mathrm{GO}^{2}=0.02$ indicated that there is difference in academic performance in Economics between students' gender. Such that the two levels of gender (factor as an independent variable) accounted for approximately 0.2 percent of the total variance in the students' Economics academic performance (the dependent variable), controlling for the effect of their attendance rate (the covariate).

Research Question III: What is the relationship between students' attendance and academic performance in Economics among Fatima High School students?

Table 5.

Pearson Correlation showing the relationship between attendance rate and academic performance in Economics among Fatima High School.

\begin{tabular}{|l|l|l|l|}
\hline \multicolumn{2}{|l|}{ Correlations } & Academic Performance & Attendance \\
\hline \multirow{3}{*}{} & Pearson Correlation & 1 & .083 \\
\cline { 2 - 4 } & Academic Performance Sig. (2-tailed) & & .267 \\
\cline { 2 - 4 } & $\mathrm{N}$ & 182 & 182 \\
\hline & Pearson Correlation & .083 & 1 \\
\cline { 2 - 4 } & Attendance Sig. (2-tailed) & .267 & 182 \\
\cline { 2 - 4 } & $\mathrm{N}$ & 182 & \\
\hline
\end{tabular}

Table 5 showed the empirical results with respect to the direction of relationship between students' attendance and academic performance. However, there is positive linear but insignificant relationship between students' attendance and academic performance. We could therefore uphold the null hypothesis which states that no significant relationship between students' attendance and academic performance in Economics among Fatima high school students. This is because, the significant level of 0.267 is more than the alpha value of 0.05 .

Research Question IV: Is there a significant difference between academic performances of Fatima High School students with high and low attendance rate?

Table 6.

T-test showing difference in academic performance of students with high and low rate of attendance

\begin{tabular}{|l|l|l|l|l|l|l|l|}
\hline Attendance Rateq11 & $\mathbf{N}$ & Mean & St. Dev & Df & $\mathbf{T}_{\text {cal }}$ & $\mathbf{T}_{\text {tab }}$ & Remark \\
\cline { 1 - 4 } High & 95 & 37.59 & 7.637 & & & $2.576^{*}$ & Sig. \\
\cline { 1 - 4 } Low & 87 & 35.20 & 6.586 & 180 & 5.872 & $1.960^{*} *$ & \\
\hline
\end{tabular}

Note: Two-Tailed Test at $1 \%$ and $5 \%$ levels of Significant.

Table 6 comprised empirical results emanated from t-test on the performance of students with high and low attendance rate in Fatima High School. Out of one-hundred and ninety two (192) students who were tutored for the examination (UPE) one-hundred and eight two of them wrote the said examination. However, ninety-five (95) of them had attendance rate greater than seventy-five percent (75\%) which was considered as having high attendance rate while the remaining ones had less than that was considered of having low rate of 
attendance for 2017/2018 academic session. The comparison of academic performance in Economics was done on two grounds that is performance of students with high attendance rate to those with low rate of attendance. The mean values of students with high and low rate of attendance stood at 37.59 marks and 35.20 marks respectively.

At $1 \%$ and $5 \%$ levels of significance with degree of freedom of 180 , the table values of t-statistics are 2.576 and 1.960 respectively showing calculated value of 5.872 (t-calculated). It is observed that critical values are less that calculated value. Therefore, we reject the null hypothesis that says there is no significant difference between the academic performances of students with high and low rate of attendance in the school. In other words, we accept that there is significant difference in the academic performance of Fatima High School students in Economics on the basis of attendance rate. This is in favour of students with high rate of attendance during 2017/2018 academic session as they had mean score which was slightly higher than their counterparts with low attendance rate.

\section{Discussion of Findings}

The assumption of homogeneity of regression slopes in adopting Analysis of Covariance (ANCOVA) was conducted with the aid of the Levene's Test of Homogeneity of Variance as well as interactive segment of the data analysis. The underline assumption of homogeneity of variance for the one-way ANCOVA was met-as evidenced by $\mathrm{F}(1,180)=4.046$. That is, $\mathrm{p}(0.176)>\alpha(0.05)$. The condition was that if the interaction is significant - the results from an ANCOVA are not meaningful and ANCOVA should not be conducted. This is because, a significant interaction between the covariate (attendance) and the factors (gender) suggested that the difference on the dependent variable (academic performance) among groups varies as a function of the covariate (attendance). The outcome lends credence to the applicability of ANCOVA, most importantly, when the interactive influence of two variables (that qualitative and quantitative) are being examined on dependent variable. This is in tandem with submission made by Aransi, (2018) in which insignificant interactive impact of students' gender and chronological age in predicting academic performance in Economics was reported which was used to validate the effectiveness of the employment of ANCOVA in testing and establishing individual effect. This is to say that the gender of the students and attendance rate correspondingly working together are insignificant in predicting academic performance in Economics. Hence, there is no significant interactive influence of gender quality and attendance rate on academic performance in Economics.

Besides, outcome from omega square with respect to gender attribute (i.e. being male or female) indicated that there is difference in academic performance in Economics between students' gender such that the two levels of gender (factor as an independent variable) accounted for approximately 0.2 percent of the total variance in the students' academic performance (the dependent variable), controlling for the effect of their attendance rate (the covariate). The weak result that emanated from this analysis may be as a results of the fact that other variables such as class stream of a learner (being Science, Commercial or Art) was not taken into cognisance as well as manifestation of individual differences irrespective of the nature of the students' gender attributes.

Also, there was positive linear but insignificant association between students' attendance and academic performance which led to uphold of the null hypothesis which states that there is no significant relationship between students' attendance and academic performance in Economics among Fatima high school students. It is clear to conclude that effort put in place by the subject teachers before, during and after classroom interaction coupled with students' access to relevant learning material are useful in complementing attendance taking so as to guarantee improvement in performance. This is in line with study conducted by Narula, and Nagar, (2013) in which timings of the classes were attributed to the correlation outcomes between the attendance and students' performance in computer related examination in two different classes. This is because, both classes do not show the same strength of correlation as first class shows a significant relationship, while, second class shows a weaker correlation in spite of the fact that it was taught by the same instructor. Similarly, as aptly reported by Aden, Yahye, and Dahir, (2013) that there is a moderate positive relationship between student attendance and academic performance. This is also corroborated by recent study conducted by Fadelelmoula, (2018) in which positive but insignificant correlation between attendance and examination performance in the courses like cardiopulmonary anatomy and physiology, cardiology and electrocardiography, respiratory care science II as well as exercise physiology and pulmonary Rehabilitation among students at Almaarefa Colleges for Science and Technology, Riyadh, Saudi Arabia was reported. 
In addition, the comparison of academic performance in Economics was done on two grounds that is performance of students with high attendance rate to those with low rate of attendance. It was observed that there is significant difference between the academic performances of students with high and low rate of attendance in the school. This is in favour of students with high rate of attendance as they had mean score slightly higher than their counterparts with low attendance rate. This may be attributed to attendance policy formulated by Fatima High school management which encouraged dual ways of reckoning with students' in terms of attendance such that class teachers are allowed to take attendance of the students in the morning at the assembly ground as well as in the afternoon coupled with classroom attendance during teaching-learning process by all subject teachers. It is clear to infer that mere emphasis on students' attendance by class teachers may not be sufficient in determining performance but setting rules and regulations on the minimum attendance standard during classroom discussion for all students attending similar educational activities without being compromised as it is being practised by some higher institutions. This is in tandem with submission made by Somalia, Keci, and Guleker, (2013) that all things being equal, the higher the attendance, the lower the probability of receiving failing grades among learners under consideration and vice-versa.

\section{Conclusion}

The study concludes that regularity and punctuality of the students not only in the school but also in the classroom during teaching-learning interaction between the teachers and the students need to be accorded great priority so as to maintain and uphold the tone of schools and thereafter stimulate academic improvement among learners.

\section{Recommendations}

Based on the findings of this study, the following recommendations are made.

i. The management of the public high schools should, as a matter of duty, verify and establish that the students coming on transfer from other sister schools do not only fulfil the academic performance criterion but also meet the minimum standard of attendance in their previous schools not minding their gender trait before considering such students for admission.

ii. The school management, either working individually or in collaboration with government or NonGovernmental bodies like Alumni Association, Parents Teachers Association Forum and the likes, should design a means of external reinforcement for the most regular and punctual student of the academic session in terms of giving an award like scholarship irrespective of the gender attribute.

iii. The subject teachers, most especially those handling Economics at the secondary school levels, should try as much as possible to form the habit of taking the attendance of students each time they enter the classroom for teaching-learning interaction and ensure that it is taken into consideration during continuous assessment grading without being partial to the gender quality of the students.

iv. Attendance status, academic performance and other vital information with respect to the conduct of each of the students in the school should be made known to the parents/guidance either through Parents Teachers Association (PTA) meeting or class teachers in order to achieve positive improvement among the learners.

v. Also, parents/guidance of students having less than half of the average attendance throughout the whole academic session except on transfer should be summoned to counselling session by the school management for orientation and such a learner may be advised to retake the class.

\section{References}

Ajayi, A. (2006). The Influence of School Type and Location on Resource Availability and Pupils Learning Outcome in Primary Schools in Ekiti State, Nigeria. Educational Thought, 5(1): 170-176.

Alimi, O. S Ehinola, G. B and Alabi, F. O (2012) School Types, Facilities and Academic Performance of Students in Senior Secondary Schools in Ondo State, Nigeria. International Education Studies: 5(3) 44-48.

Alufohai, P. J (2016) School-Based Factors Affecting Senior Secondary School Students' Achievement in English Language in Edo State, European Journal of Research and Reflection in Educational Sciences, 4(9); 36-43.

Aransi, W. O (2018) The Influence of School Types, Class Classifications and Gender on Academic Achievement in Economics among High School Students: A Comparative Analysis. International Journal of Progressive Sciences and Technologies (IJPSAT); 8(2), 120-128.

Aransi, W. O. (2018) Impact of Age and Gender on High School Students' Academic Performance in Economics: A Case Study Analysis. International Journal for Innovative Research in Multidisciplinary Field, 4(1); 8-15. 
Boniface U. E (2018) Classroom Environment And Academic Interest as Correlates of Achievement in Senior Secondary School Chemistry in Ibadan South West Local Government Area, Oyo State, Nigeria, Global Journal of Educational Research, 17; 61-71.

Bonsu, H. D (2016) A Comparative Analysis of Academic Performance of Public and Private Junior High Schools in the Basic Education Certificate in Sekondi/Takoradi, European Journal of Basic and Applied Sciences 3 (1); 2 1-32.

Considine, G. and Zappala, G. (2002). The influence of Social Economic disadvantage in the academic performance of school students in Australia. Journal Sociology, 38, 127-148.

Daso, P. O (2013) Teacher Variables and Senior Secondary Students' Achievement in Mathematics in Rivers State, Nigeria. European Scientific Journal, 9 (10); 271-289.

Fadelelmoula T, (2018) The impact of class attendance on student performance. International Research Journal of Medicine and Medical Sciences, 6(2): 47-49.

Falsario, H. N., Muyong, R. F and Nuevaespang, J. S., (2014). Classroom climate and academic performance of education students. Research report presented at DLSU Research Congress De La Salle University,Manilla, Philippines, March 6-8.

Farooq, M.S. Chaudhry, A.H. Shafiq, M. and Berhanu, G. (2011) Factors Affecting Students' Quality of Academic Performance: A Case Of Secondary School Level, Journal of Quality and Technology Management; VII (II), 01 - 14

https://www.myschoolgist.com/ng/waec-may-june-results-statistics

Kassarnig V, Bjerre-Nielsen A, Mones E. Lehmann S, Lassen D. D (2017) Class attendance, peer similarity, and academic performance in a large field study. Accessed https://journals.plos.org/plosone/article?id=10.1371/journal.pone.0187078on 17/10/2018 12(11):

Keci, J and Guleker, R (2013) The Effect of Attendance on Academic Performance, Mediterranean Journal of Social Sciences, 5 (23), 961-966

Kosoko-Oyedeko, G. A (2008) Correlate of Teachers Profiles and Pupils Academic achievement, The Social Science, 3(1); 6-11.

Narula, M and Nagar, P (2013) Relationship between Students' Performance and Class Attendance in a Programming Language Subject in a Computer Course. International Journal of Computer Science and Mobile Computing (IJCSMC); 2(8), $206-210$.

Odinko, M.N., (2002) Home and School Factor as determinants of Literacy Skill Development among Nigeria Preprimary School Children, Unpublished Ph.D. Thesis University of Ibadan, Ibadan,

Aden, A. A Yahye, Z. A and Dahir, A. M (2013) The Effect of Student's Attendance on Academic Performance: A Case Study At Simad University Mogadishu, Academic Research International, 4(6); 409-417.

Oginni, A. M Awobodu, V. Y Alaka, M. O and Saibu, S.O (2013) School Factors as Correlates of Students' Achievement in Chemistry, International Journal for Cross-Disciplinary Subjects in Education (IJCDSE), 3 (3);1516-1523.

Okonkwo, S.C. (2002) "Relationship between some school and teacher variables and students' achievement in Mathematics”, Journal of science Teachers Association of Nigeria $35 \quad$ (1 E 2), $43-49$

Olorundare, A. S (2011) Correlates of poor academic performance of secondary school students in the sciences in Nigeria. A paper presented at Virgina State Unversity, Petersburg, Virginia, U.S.A.

Ouma, N. O and Munyua, J. K (2018) Relationship between Teachers' Working Conditions and Students' Academic Performance in Public Day Secondary Schools in Nyando Sub-County, Kenya. British Journal of Education, 6(5);52-58.

Owoeye, J S and Yara, P.O (2011) School Location and Academic Achievement of Secondary School in Ekiti State, Nigeria. Asian Social Science,7(5); 170-175.

Philias, O. Y., and Wanjobi, W. C. (2011). Performance Determinants of Kenya Certificate of Secondary Education (KCSE) in Mathematics of Secondary Schools in Nyamaiya Division, Kenya. Asian Social Science, 7 (2), 107112.

Robert, A. K (2015) School Attendance is a Pre-Requisite for Student Academic Performance in Universal Secondary Education Schools. Journal of Social Science for Policy Implications; 3(1), 33-57. 